\title{
The Awareness and Adoption of Artificial Intelligence for Effective Facilities Management in the Energy Sector
}

\author{
Jonathan Oluwapelumi, MOBAYO ${ }^{1(\bowtie)}$ \\ ${ }^{1}$ Federal University of Technology Minna, Niger State, Nigeria \\ pelumobayo@gmail.com \\ Ayooluwa Femi ARIBISALA², \\ Saheed Olanrewaju YUSUF ${ }^{3}$, \\ Usman BELGORE ${ }^{4}$ \\ 2,3,4 Federal University of Technology Minna, Niger State, Nigeria.
}

\begin{abstract}
Most sectors of the Nigerian economy, including the energy sector, have been infiltrated by digital technologies, including artificial intelligence (AI), where they have been extensively investigated. The research aims primarily to assess the perception of AI in facility management and identify the prospects and challenges of the adoption of AI in the energy sector. The study adopted the quantitative methodology approach, using a structured questionnaire to a sample size of 384 respondents. The questionnaire was administered to professionals such as mechanical, civil, electrical, computer, and mechatronics engineers and project managers within the North-central geopolitical zone of Nigeria. Data gathered was analyzed using descriptive analysis (mean value, weighted total, and relative importance index). The study based on findings concludes that there is a high awareness level about AI in the energy sector. Also, awareness about some selected AI technologies, machine \& deep learning, robotics, and speech recognition had a high awareness level. The study also concludes that improved energy management, efficiency and transparency, remote reading of energy meters, and improved planning, operation \& control of power systems were prevalent prospects of AI adoption. The major challenging factors to adopting AI in the Nigerian energy sector are outdated power system infrastructure, cellular technologies, a scarcity of qualified experts and data scientists, and a growing threat from cyber-attacks. The study recommends improved awareness and technical know-how of energy sector personnel and adequate power system infrastructure to provide a stable power supply.
\end{abstract}

Keywords-Artificial intelligence, Awareness, Energy Sector, Facilities management 


\section{Introduction}

Artificial intelligence (AI) is a type of "deep learning" that enables machines to analyze information on a very sophisticated level on their own, allowing them to perform complicated functions such as facial recognition and speech recognition [1]. According to [2], AI systems can quickly extract insights from massive, heterogeneous data sets and discover correlations that might otherwise go missed by humans. As a result, $\mathrm{AI}$ is a powerful tool for improving people's daily lives [3]. From self-driving cars and industry automation to smart home apps like Siri and Alexa, AI has significantly impacted society [4]. AI has become one of the most advanced technologies used in numerous industries in the twenty-first century. The primary motivation for implementing AI is to combine multiple areas like medicine, renewable power, and education [5].

Artificial intelligence is commonly employed for solar power plant irradiance prediction and estimated power output, as well as wind speed prediction and projected power output from wind farms [4]. Recently, end-to-end technology such as artificial intelligence robotics and wireless communications have been developed and widely used for energy digitization [6]. The utility business is undergoing a shift from a steady environment to a volatile, technology-driven environment [7]. Hence, AI in collaboration with other technologies can be effective instruments for resolving issues and supporting key stakeholders in making complex decisions during power networks' planning, execution, and maintenance phases. Furthermore, the advanced application of AI in the power sector is crucial in smart-grid set-ups, notably timely fault discovery and enhanced forecast for renewable energy [8]. According to [9], artificial intelligence can help the energy business capitalize on the expanding opportunities created by digital technologies and the incorporation of renewables. Energy generation, distribution, and finances required are critical to the global economy [4]. These cannot be achieved with the present electrical grid infrastructure, which is outdated with insufficient fault protection. AI advancements are revolutionizing the energy business the emerging technologies. AI has been utilized to accomplish a wide range of tasks, leading to improved performance of the sector [10]. [6] made a detailed description of some tasks of AI in the Energy Industry (see Figure 1). 


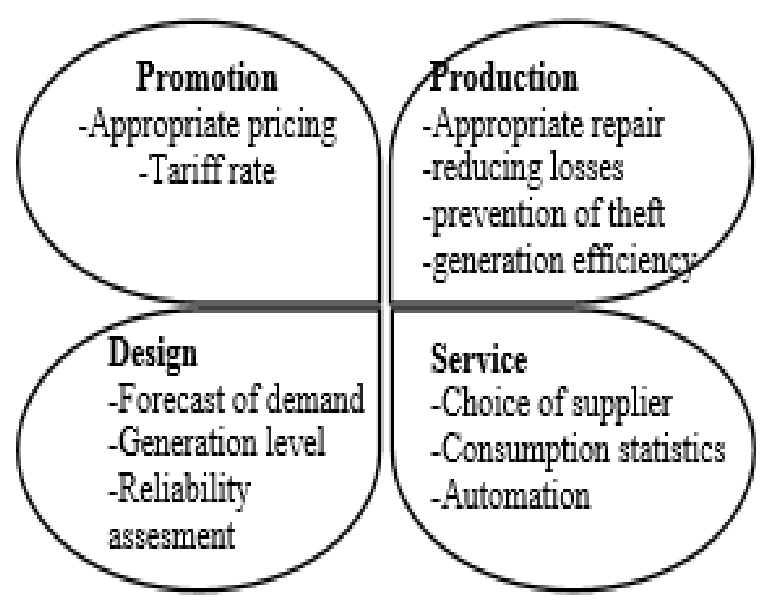

Fig. 1: Tasks of AI in Energy Industry [6]

Application of AI in photovoltaic (PV) systems improves inverter management and increases the ability to track power points [11]; [12]; [13]. Artificial maximum power point tracking (MPPT) techniques are more operational and can increase output when compared to regular MPPT processes [14]. AI systems, when correctly created, can be especially valuable for automated routine and structured procedures, allowing humans to deal with tomorrow's power concerns. The ability to provide clean, affordable energy, which is critical for sustainable development, is inextricably linked to AI [15]. AI and machine learning (ML) methods such as the Artificial Neural Network (ANN) and Random Forest (RF) are computationally efficient and accurate in forecasting energy consumption, cyber-attack, predictive maintenance, and facility management [16];[17]; [18]; [19].

Most developed countries have used artificial intelligence to grow every aspect of their economies to become world powers. Although we now live in a time when AI is taking over many jobs, almost everything in Nigeria is done manually [1]. Unstable supply and demand, inefficiency, and a lack of critical analysis essential for optimal administration pose new challenges to the energy sector [15]. Despite its relevance and progress in terms of innovation, AI has experienced several difficulties, particularly in developing countries such as Nigeria. Complex algorithms, AI human interface, cultural and religious barriers, software malfunction, and a decline in investment are some of the challenges identified by [1]. AI concerns can be solved systematically by transferring expertise from the power sector to AI software firms [15]. Some people believe that if Artificial Intelligence (AI) continues to advance unabated, it will threaten humanity. Others believe that, unlike previous technological revolutions, Artificial Intelligence (AI) will increase the risk of mass unemployment. This implies that artificial 
intelligence is involved in the project of developing machines endowed with humanlike cognitive processes and attributes such as reasoning, seeking answers, or learning from previous scenarios [1]. Similarly, Artificial Intelligence can be used to shape the growth of key sectors in the Nigerian economy. Indeed, the applications of AI technology will be the best technology for boosting core sectors and assisting Nigeria in its rapid digitization [1]. According to [6], the employment of artificial intelligence in the power industry will reduce power supply interruptions. [20] underlined that numerous opportunities such as digital progression and national development by adopting information and communication technologies (ICTs).

Empirical findings revealed that [5] highlighted the AI technologies adopted in power systems. [21] investigated how artificial intelligence impacts the solar photovoltaic value chain. Research [22] in their study explored the drawbacks, future opportunities of solar energy in selected countries in Asia, Africa, and South America. [1] also studied the importance, challenges, and applications of artificial intelligence in Nigeria. [23] reviewed the relevance of Artificial Intelligence in Indian industries at present and to the future. Unlike the existing literature contributions, this paper assesses the awareness of AI in facility management and identifies the prospects and challenges of the adoption of AI in the energy sector. Furthermore, the identification of the opportunities and obstacles of using $\mathrm{AI}$ is presented empirically. The study further provides insights into AI's broad topic for successful facility management. This research would help build the groundwork for identifying new strategies, provide additional insight into managing complicated electrical set-ups through AI, and aid in decision-making.

\section{Material and Methods}

The study adopted the quantitative methodology approach. This method entails data gathering, which may be subjected to further quantitative analysis in a formal manner [24]. Furthermore, data analysis is significantly easier and less error-prone using this technique [25]. As a result, the authors used a questionnaire to collect primary data from a sample size of 384 using the Cochran's formula. This method was used since the research population could not be determined.

$$
n_{0}=\frac{Z^{2} p q}{e^{2}}
$$

$$
\begin{aligned}
& \text { Where } \quad \mathrm{e}=.05 \\
& \mathrm{p}=.5 \\
& \mathrm{q}=1-\mathrm{p}=.05 \\
& \mathrm{z}=1.96
\end{aligned}
$$


Thus

$n_{0}=\frac{1.96^{2}(0.5 * 0.5)}{0.05^{2}}$

$$
\mathrm{n}_{0}=384
$$

The questionnaire was administered to professionals such as mechanical, civil, electrical, and mechatronics engineers, quantity surveyors, architects, and project managers within the North-central geopolitical zone (Plateau, Kogi, Kwara, Nassarawa, Niger States, Benue, and the Federal Capital Territory (FCT) Abuja) of Nigeria (see Figure 2 ). These professionals work with energy-oriented organizations within the study area. The choice of the North-central geopolitical zone was motivated due to proximity, convenience, and predominant economic development of the region. Additionally, Niger state within the zone has three hydroelectric power plants which distribute power supply to neighboring states.

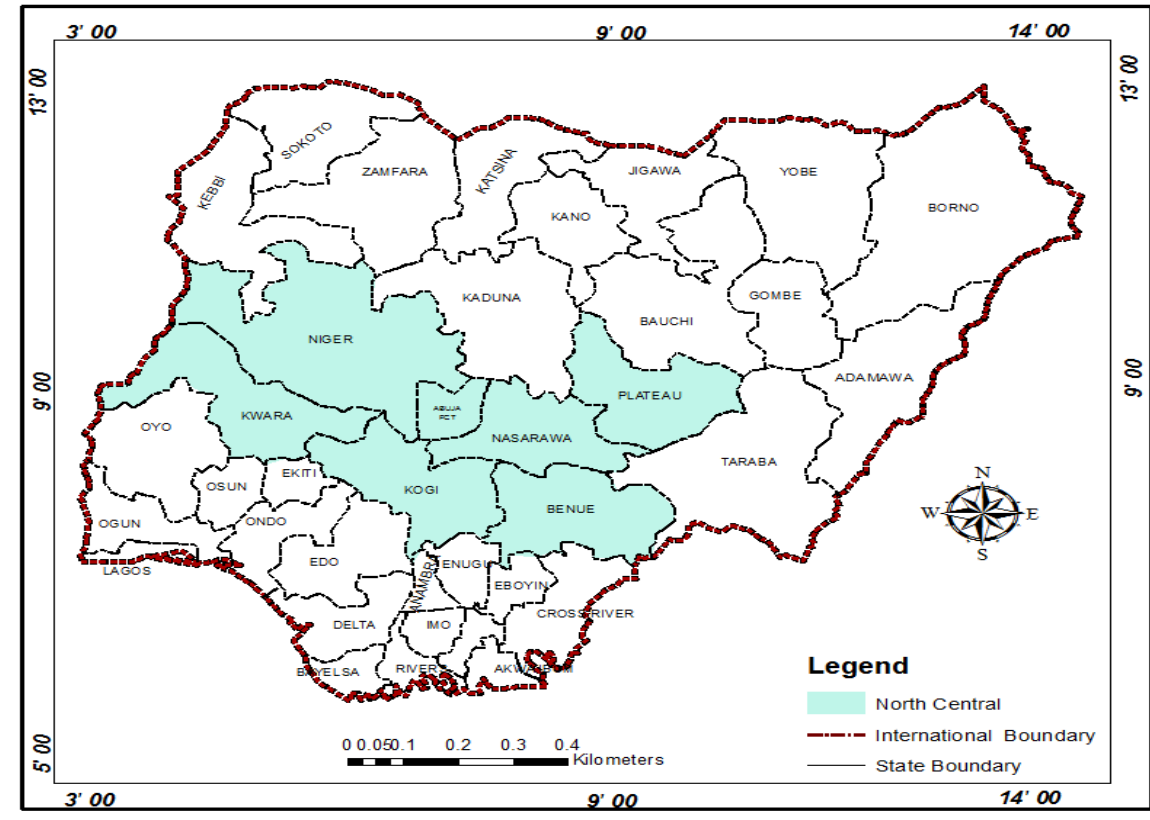


The research instrument used for data collection was divided into three main sections. The first part asked respondents about personal details (such as; state, academic qualification, profession, organization category, and years of practice). The other two sections asked questions relating to the awareness of $\mathrm{AI}$ in facilities management and to identify the prospects and challenges of adopting AI in the Nigerian energy sector. The random method was the adopted Sampling technique, while Statistical Package for the Social Sciences (SPSS) was employed for descriptive analysis. Additionally, weighted index (WI) was further used for analysis to ascertain the level of awareness (WAI) of AI technologies and level of application. This approach was also adopted by [26] and [27].

$$
W I=\frac{\sum_{i=0}^{5} a i x i}{5 \sum_{i=0}^{5} x i} \quad(0 \leq \mathrm{WI} \leq 1)
$$

Where $\mathrm{ai}=$ constant expressing the weight given to a group

$$
x i=\text { frequency of response }
$$

A value of WI approaching 1 signifies high respondent's agreement on variable factors measured. Hence, the higher the weighted total (WT), the higher the weighted index (WI), and the higher the level of agreement among respondents for a given variable factor.

\section{$3 \quad$ Results and Discussion}

\subsection{Background data of respondents}

The data analysis was based on 287 valid responses (74.7\% return rate) retrieved from 384 administered questionnaires. The high response rate indicates the willingness of respondents to take part in the survey while the remaining 97 questionnaires were either incomplete or not returned and, as a result, were disqualified. The background data of respondents is presented in Table 1.

Table 1. Background data of respondents

\begin{tabular}{|l|c|c|}
\hline Profile & Frequency & Percentage \\
\hline Gender & 193 & 67.2 \\
\hline Male & 94 & 32.8 \\
\hline Female &
\end{tabular}




\begin{tabular}{|c|c|c|}
\hline Academic Qualification & & \\
\hline NCE/ND & 21 & 7.3 \\
\hline $\mathrm{HND} / \mathrm{BSC}$ & 138 & 48.1 \\
\hline MBA/MSC/M.Eng & 84 & 29.3 \\
\hline $\mathrm{PhD}$ & 44 & 15.3 \\
\hline \multicolumn{3}{|l|}{ Industry Professionals } \\
\hline Project Manager & 58 & 20.2 \\
\hline Electrical Engineer & 62 & 21.6 \\
\hline Mechanical Engineer & 47 & 16.4 \\
\hline Civil Engineers & 48 & 16.7 \\
\hline Mechatronics Engineer & 12 & 4.2 \\
\hline Computer Engineer & 33 & 11.5 \\
\hline Other & 27 & 9.4 \\
\hline \multicolumn{3}{|l|}{ Years of Experience } \\
\hline $1-5$ & 42 & 14.6 \\
\hline $6-10$ & 46 & 16.0 \\
\hline $11-15$ & 75 & 26.1 \\
\hline $16-20$ & 77 & 26.8 \\
\hline 0ver 20 & 47 & 16.4 \\
\hline
\end{tabular}

The results showed that males account for $67.2 \%$ while females account for $32.8 \%$; this implies that there are more male industry professionals in the energy sector. The survey of the educational qualifications showed that $7.3 \%$ have NCE/ND, $48.1 \%$ have HND/BSC, 29\%.3 have a master's degree, and 15.3\% had PhD; this indicates that the respondents have the fundamental and necessary educational credentials to offer response required to support the conclusions of this study. The respondents were further distributed as Project Managers (20.2\%), Electrical Engineers (21.6\%), Mechanical Engineers (16.4\%), Civil Engineers (16.7\%), Mechatronics Engineers (4.2\%), Computer Engineers $(11.5 \%)$, and others $(9.4 \%)$. About $26.8 \%$ of the respondents had experience spanning $16-20$ years while $14.6 \%$ had the least experience of $1-5$ years. This further implies that industry professionals are experienced in their various fields and have also developed extensive expertise in handling industry-related challenges; as a consequence, the data gathered is reliable and appropriate.

\subsection{Awareness of Artificial Intelligence (AI) in the Energy Sector}

Figure 3 depicts respondents' understanding of the idea of Artificial Intelligence. According to the study's findings, most respondents (76\%) had heard of AI, while $24 \%$ 
had never heard of the notion. The findings might be ascribed to the current understanding of the notion through the internet, social media, television shows, and seminars, among other things.

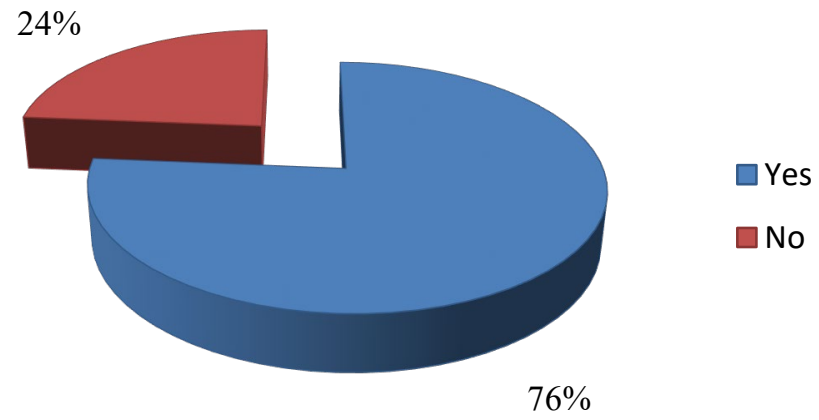

Fig. 3. Awareness regarding the concept of AI

Respondents were also asked to rate their level of awareness of a variety of AI technologies mentioned in the literature using a 5-points Likert scale, with "1" indicating the least level of awareness and "5" representing the highest level of awareness. Their level of awareness was ranked 'high' and 'low' using the respective mean score under each variable. The knowledge regarding AI technologies is presented in Table 2.

Table 2: Awareness regarding AI technologies

\begin{tabular}{|l|l|c|c|c|c|c|c|c|c|c|}
\hline S/No & AI Technologies & $\mathbf{1}$ & $\mathbf{2}$ & $\mathbf{3}$ & $\mathbf{4}$ & $\mathbf{5}$ & Mean & $\begin{array}{c}\text { Weighted } \\
\text { Awareness } \\
\text { Total }\end{array}$ & $\begin{array}{c}\text { Weighted } \\
\text { Awareness } \\
\text { Index }\end{array}$ & $\begin{array}{c}\text { Level of } \\
\text { Awareness }\end{array}$ \\
\hline 1 & Machine Learning & 36 & 43 & 69 & 80 & 59 & 3.29 & 944 & 0.658 & High \\
\hline 2 & Deep Learning & 50 & 47 & 46 & 86 & 58 & 3.19 & 916 & 0.638 & High \\
\hline 3 & Neural Network & 78 & 71 & 62 & 54 & 22 & 2.55 & 732 & 0.510 & Low \\
\hline 4 & Expert System & 63 & 71 & 72 & 61 & 20 & 2.67 & 765 & 0.533 & Low \\
\hline 5 & Fuzzy logic & 87 & 73 & 56 & 40 & 31 & 2.49 & 716 & 0.499 & Low \\
\hline
\end{tabular}


Journal of Digital Food, Energy \& Water Systems, 2 (2): 1-18, 2021

ISSN 2709-4529

(C) Centre for Cyber Physical Food, Energy \& Water Systems

\begin{tabular}{|l|l|l|l|l|l|l|l|c|c|c|}
\hline S/No & AI Technologies & $\mathbf{1}$ & $\mathbf{2}$ & $\mathbf{3}$ & $\mathbf{4}$ & $\mathbf{5}$ & Mean & $\begin{array}{c}\text { Weighted } \\
\text { Awareness } \\
\text { Total }\end{array}$ & $\begin{array}{c}\text { Weighted } \\
\text { Awareness } \\
\text { Index }\end{array}$ & $\begin{array}{c}\text { Level of } \\
\text { Awareness }\end{array}$ \\
\hline 6 & $\begin{array}{l}\text { Natural Language } \\
\text { Processing }\end{array}$ & 69 & 36 & 78 & 56 & 48 & 2.92 & 839 & 0.585 & Low \\
\hline 7 & Robotics & 5 & 11 & 94 & 84 & 77 & 3.8 & 1030 & 0.718 & High \\
\hline 8 & $\begin{array}{l}\text { Speech Recogni- } \\
\text { tion }\end{array}$ & 27 & 47 & 95 & 75 & 43 & 3.21 & 921 & 0.642 & High \\
\hline \multicolumn{7}{|c|}{$1=$ NA; 2 SA; 3 SWA; 4=MA; 5=EA } \\
\hline
\end{tabular}

Further analysis using weighted awareness index (WAI) show the existence of high awareness of AI technologies such as robotics (0.718), machine learning (0.658), speech recognition $(0.642)$ and deep learning $(0.638)$ while natural language processing (0.585), expert system (0.533), neural network (0.510) and fuzzy logic (0.499) all have low awareness level as presented in Figure 4.

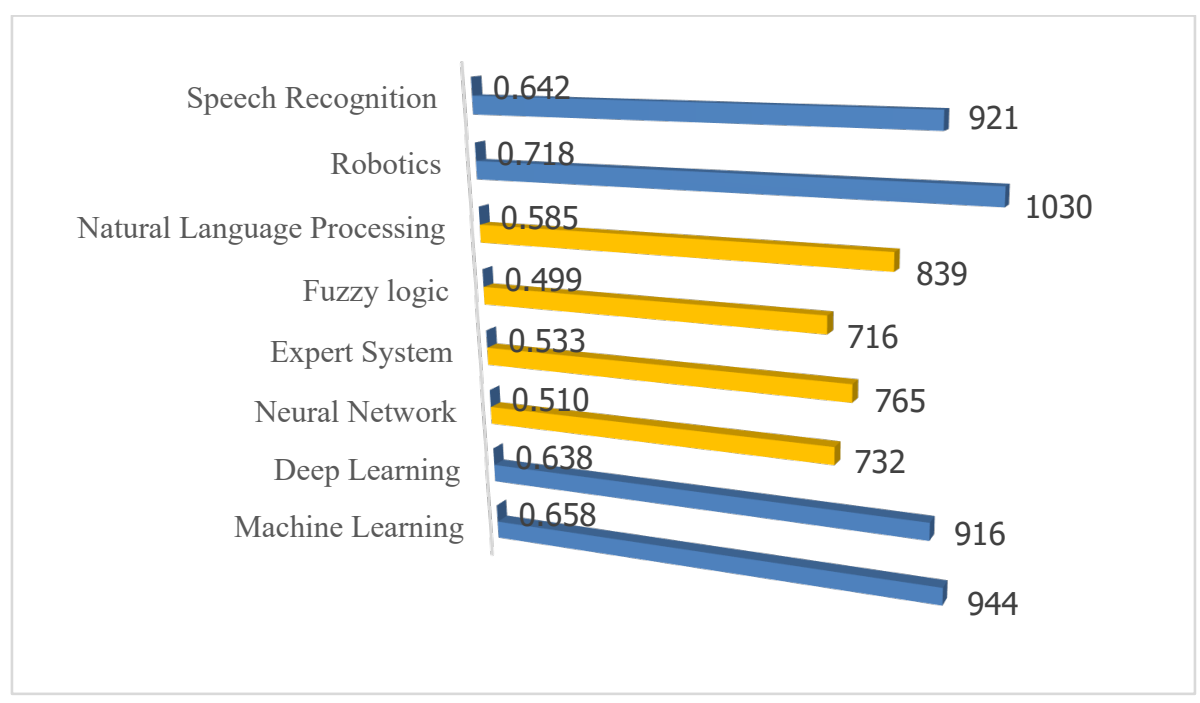

Fig. 4. Awareness level of AI technologies

To determine the level of knowledge of AI, respondents were asked to rank their level of awareness of AI applications in the energy industry. Table 3 summarizes the findings, categorizing the level of awareness as "high" or "low." 
Table 3: Awareness regarding AI applications in the energy sector

\begin{tabular}{|c|l|c|c|c|c|c|c|c|c|c|}
\hline S/No & AI Technologies & $\mathbf{1}$ & $\mathbf{2}$ & $\mathbf{3}$ & $\mathbf{4}$ & $\mathbf{5}$ & Mean & $\begin{array}{c}\text { Weighted } \\
\text { Awareness } \\
\text { Total }\end{array}$ & $\begin{array}{c}\text { Weighted } \\
\text { Awareness } \\
\text { Index }\end{array}$ & $\begin{array}{c}\text { Level of } \\
\text { Awareness }\end{array}$ \\
\hline 1 & Digitalized Power Generation & 42 & 39 & 80 & 69 & 57 & 3.21 & 921 & 0.642 & Low \\
\hline 2 & $\begin{array}{l}\text { Advanced Metering Infra- } \\
\text { structure }\end{array}$ & 25 & 27 & 53 & 96 & 86 & 3.67 & 1052 & 0.733 & High \\
\hline 3 & Energy Storage Analytics & 52 & 68 & 71 & 45 & 51 & 2.91 & 836 & 0.583 & Low \\
\hline 4 & Smart Grid & 28 & 38 & 81 & 78 & 62 & 3.38 & 969 & 0.675 & High \\
\hline 5 & Network Management & 29 & 35 & 69 & 76 & 78 & 3.48 & 1000 & 0.697 & High \\
\hline 6 & $\begin{array}{l}\text { Energy Efficiency Decision } \\
\text { Making }\end{array}$ & 39 & 48 & 77 & 68 & 55 & 3.18 & 913 & 0.636 & Low \\
\hline 7 & $\begin{array}{l}\text { Fault Prediction and Detec- } \\
\text { tion }\end{array}$ & 37 & 50 & 56 & 75 & 69 & 3.31 & 950 & 0.662 & High \\
\hline 8 & $\begin{array}{l}\text { Renewable Energy Forecast- } \\
\text { ing }\end{array}$ & 45 & 55 & 77 & 56 & 54 & 3.07 & 880 & 0.613 & Low \\
\hline & $1=$ NA; $2=$ SA; $3=$ SWA; $4=$ MA; $5=$ EA \\
\hline
\end{tabular}

The result using weighted awareness index (WAI) shows that there is a low level of awareness in AI's application in digitalized power generation (0.642), energy efficiency decision making (0.636), renewable energy forecasting (0.613), and energy storage analytics ( 0.583$)$ among the respondents while the application of AI in advanced metering infrastructure (0.733), network management (0.697), smart grid (0.675) and fault prediction/detection (0.662) all registered a high level of awareness as presented in Figure 5. 
Journal of Digital Food, Energy \& Water Systems, 2 (2): 1-18, 2021

ISSN 2709-4529

(C) Centre for Cyber Physical Food, Energy \& Water Systems

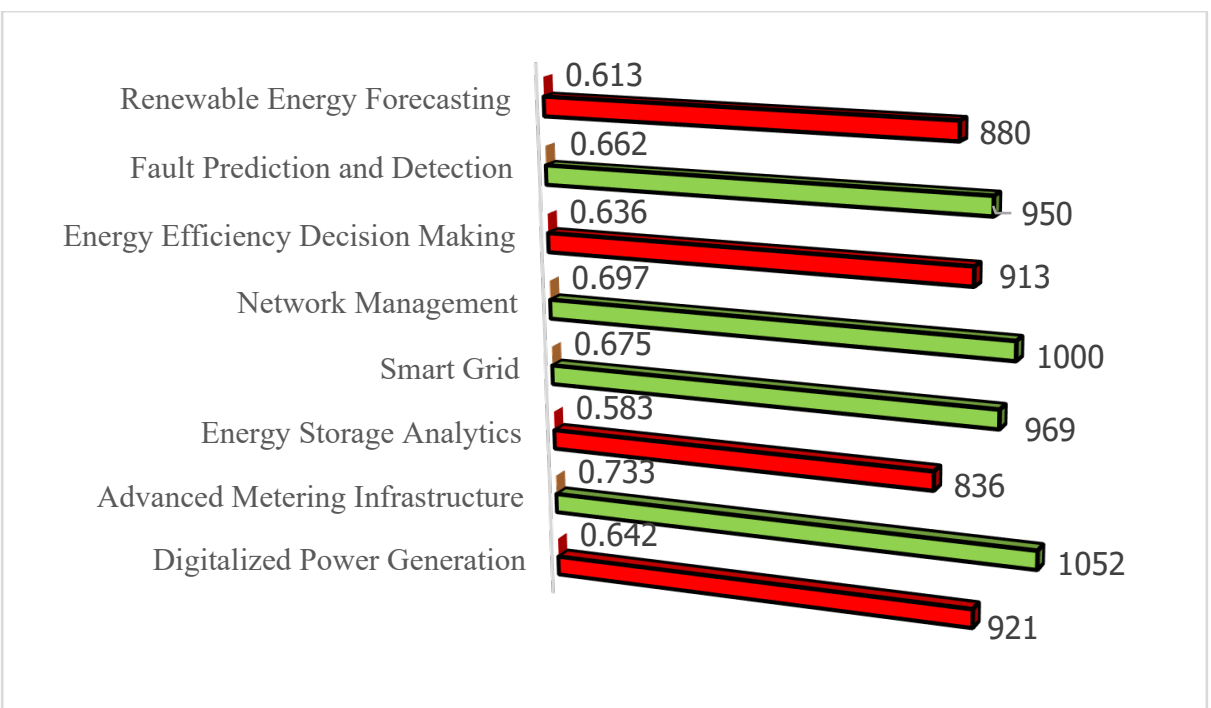

Fig. 5. Awareness level of AI Applications

The respondents were questioned if there is a personnel committed to or in charge of AI in their respective organizations. The results presented in Figure 6 showed that $86 \%$ do not have designated group/personnel responsible for AI in their organizations, while $9 \%$ have a dedicated group.

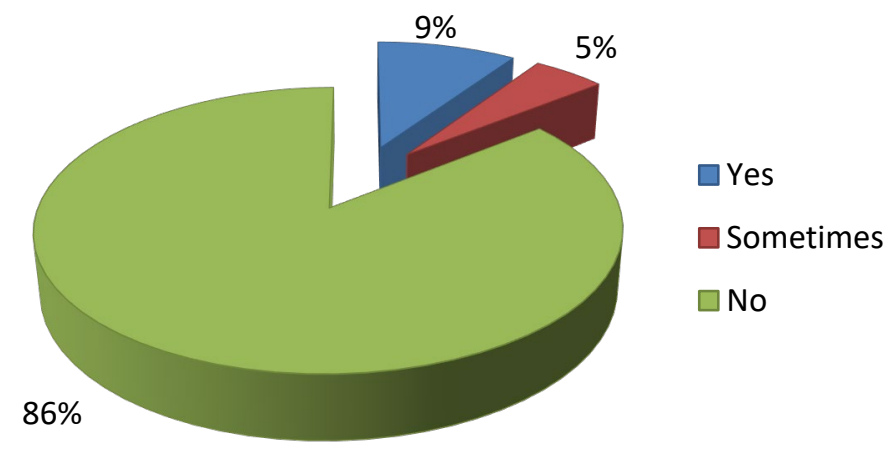

Fig. 6: Designated Group or Personnel Responsible for AI

\subsection{Prospects of the adoption of artificial intelligence in the energy sector}

Another objective of this research was to determine the prospects of AI in the energy sector. Extracts from the studies of [9]; [20] and [22], twelve prevailing prospects AI 
may be useful to the energy sector was drawn. On a 5-point Likert scale, respondents were requested to view their opinion. Table 4 shows the prospect of AI adoption in the energy sector.

Table 4: Prospects of AI adoption in the energy sector

\begin{tabular}{|c|c|c|c|c|c|c|c|c|c|}
\hline Prospects & 1 & 2 & 3 & 4 & 5 & Mean & $\begin{array}{c}\text { Weighted } \\
\text { Total } \\
\end{array}$ & $\begin{array}{l}\text { Weighted } \\
\text { Index }\end{array}$ & Rank \\
\hline $\begin{array}{l}\text { Improved energy management, } \\
\text { efficiency and transparency }\end{array}$ & 10 & 19 & 37 & 124 & 97 & 3.97 & 1140 & 0.794 & 1 \\
\hline $\begin{array}{l}\text { Remote reading of energy me- } \\
\text { ters }\end{array}$ & 10 & 15 & 48 & 117 & 97 & 3.96 & 1137 & 0.792 & 2 \\
\hline $\begin{array}{l}\text { Improved planning, operation } \\
\text { and control of power systems }\end{array}$ & 18 & 19 & 43 & 110 & 97 & 3.87 & 1110 & 0.774 & 3 \\
\hline $\begin{array}{l}\text { Improved forecasts of electricity } \\
\text { demand and generation }\end{array}$ & 10 & 24 & 57 & 101 & 95 & 3.86 & 1108 & 0.772 & 4 \\
\hline $\begin{array}{l}\text { Detection and Prediction of } \\
\text { Fault }\end{array}$ & 15 & 24 & 40 & 114 & 94 & 3.86 & 1109 & 0.773 & 5 \\
\hline $\begin{array}{l}\text { Power quality monitoring and } \\
\text { renewable energy forecasting }\end{array}$ & 12 & 24 & 54 & 103 & 94 & 3.85 & 1104 & 0.769 & 6 \\
\hline $\begin{array}{l}\text { Automation of routine and struc- } \\
\text { tured tasks }\end{array}$ & 15 & 23 & 58 & 102 & 89 & 3.79 & 1088 & 0.758 & 7 \\
\hline $\begin{array}{l}\text { Improved reliability, security } \\
\text { and efficiency of electricity } \\
\text { transmission and distribution }\end{array}$ & 19 & 34 & 33 & 107 & 94 & 3.78 & 1084 & 0.755 & 8 \\
\hline $\begin{array}{l}\text { Prevention of losses due to infor- } \\
\text { mal connections and energy theft }\end{array}$ & 20 & 25 & 59 & 97 & 86 & 3.71 & 1065 & 0.742 & 9 \\
\hline $\begin{array}{l}\text { Encourage and hasten the adop- } \\
\text { tion of clean renewable energy } \\
\text { sources. }\end{array}$ & 23 & 29 & 49 & 97 & 89 & 3.7 & 1061 & 0.739 & 10 \\
\hline Lower energy waste and costs & 25 & 33 & 49 & 97 & 83 & 3.63 & 1041 & 0.725 & 11 \\
\hline $\begin{array}{l}\text { Improved assessment of dam- } \\
\text { ages and disaster recovery }\end{array}$ & 25 & 32 & 63 & 95 & 72 & 3.55 & 1018 & 0.709 & 12 \\
\hline \multicolumn{10}{|c|}{$1=\mathrm{SD} ; 2=\mathrm{D} ; 3=\mathrm{N} ; 4=\mathrm{A} ; 5=\mathrm{SA}$} \\
\hline
\end{tabular}


Descriptive statistics using mean, weighted total (WT), and weighted index (WI) was used to analyse the identified prospects. According to the results, 'improved energy management, efficiency and transparency' (WI=0.794); 'remote reading of energy meters' (WI $=0.792)$; 'improved planning, operation and control of power systems' $(\mathrm{WI}=0.774)$ ranked first, second and third respectively while 'accelerate the use of clean renewable energy sources' (WI $=0.739)$; 'lower energy waste and costs' (WI $=0.725)$; 'improved assessment of damages and disaster recovery' (WI $=0.709$ ) ranked tenth, eleventh and twelfth respectively. The results support [15]; and [14] that AI can potentially change contemporary energy systems and effective facility management in the energy sector. AI improves estimates of electricity demand and generation, allowing the demand-supply balance. Furthermore, artificial intelligence tends to minimize energy wastage, slash energy prices, and expedite the deployment of cleaner energy sources. AI may also aid in designing, operating, and controlling power systems.

\subsection{Factors challenging the adoption of $\mathrm{AI}$ in the energy sector}

Adopting and deploying AI in the energy sector presents a number of challenges. Eight common factors were identified from literature [22]; [15]; [1] to highlight the challenges associated with the adoption of AI, while others were identified via conversations with experts. The results presented in Table 5 is based on a 5-points Likert scale.

Table 5. Factors challenging the adoption of AI in the energy sector

\begin{tabular}{|l|c|c|c|c|c|c|c|c|c|}
\hline Challenges & $\mathbf{1}$ & $\mathbf{2}$ & $\mathbf{3}$ & $\mathbf{4}$ & $\mathbf{5}$ & Mean & $\begin{array}{c}\text { Weighted } \\
\text { Total }\end{array}$ & $\begin{array}{c}\text { Weighted } \\
\text { Index }\end{array}$ & Rank \\
\hline Outdated power system infrastructure & 12 & 15 & 33 & 118 & 109 & 4.03 & 1158 & 0.807 & 1 \\
\hline Cellular technologies & 15 & 19 & 37 & 113 & 103 & 3.94 & 1131 & 0.788 & 2 \\
\hline Scarcity of skilled professionals & 18 & 20 & 29 & 115 & 105 & 3.94 & 1130 & 0.787 & 3 \\
\hline Growing threat from cyber attacks & 14 & 24 & 36 & 112 & 101 & 3.91 & 1123 & 0.783 & 4 \\
\hline $\begin{array}{l}\text { AI is dependent on electricity and internet } \\
\text { connections }\end{array}$ & 18 & 23 & 37 & 97 & 112 & 3.91 & 1123 & 0.783 & 4 \\
\hline Data quality issues & 15 & 20 & 38 & 117 & 97 & 3.91 & 1122 & 0.782 & 6 \\
\hline Lack of dedicated AI policy and regulation & 15 & 24 & 40 & 111 & 97 & 3.87 & 1112 & 0.775 & 7 \\
\hline Legal security concerns and user privacy & 17 & 25 & 54 & 98 & 93 & 3.78 & 1086 & 0.757 & 8 \\
\hline The concept of AI models is unknown to users & 18 & 26 & 54 & 101 & 88 & 3.75 & 1076 & 0.750 & 9 \\
\hline Integration of AI into subsystems & 19 & 30 & 52 & 97 & 89 & 3.72 & 1068 & 0.744 & 10 \\
\hline Decentralization and diversification & 25 & 32 & 57 & 94 & 79 & 3.59 & 1031 & 0.718 & 11 \\
\hline
\end{tabular}


Journal of Digital Food, Energy \& Water Systems, 2 (2): 1-18, 2021

ISSN 2709-4529

(c) Centre for Cyber Physical Food, Energy \& Water Systems

\begin{tabular}{|l|c|c|c|c|c|c|c|c|c|}
\hline Possible job loss within the energy sector & 28 & 31 & 54 & 96 & 78 & 3.57 & 1026 & 0.715 & 12 \\
\hline Generate questions on transparency & 31 & 40 & 65 & 86 & 65 & 3.4 & 975 & 0.679 & 13 \\
\hline
\end{tabular}

Similarly, descriptive statistics using mean, weighted total (WT), and weighted in$\operatorname{dex}(\mathrm{WI})$ were used to analyze the identified challenges. The findings showed that 'outdated power system infrastructure' (WI $=0.807)$; 'cellular technologies' $(\mathrm{WI}=0.788)$; 'scarcity of skilled professionals' (WI $=0.787$ ); and 'growing threat from cyber-attacks cellular technologies' (WI=0.783) were the major challenges identified by respondents. In addition, 'decentralization and diversification' (WI $=0.718$ ); 'possible job loss' (WI=0.715); and 'generate questions on transparency' (WI=0.679) ranked lowest. According to [14], several factors prevent broader AI adoption, such as difficulties with data quality and legal issues. The findings from the study also corroborate with that of [28] and [29] who opined that AI is reliant on infrastructures such as energy and internet connectivity. There are few datasets accessible for AI projects, and the provided data is of uncertain quality. As a result, many targeted AI and ICT initiatives fail to offer the benefits requirement to the project's sponsors owing to incorrect and inadequate data.

Furthermore, in underdeveloped nations such as Nigeria, cities, outlying areas, and villages lack regular power supplies and reliable internet coverage. The lack of these requisite infrastructures poses a significant barrier to using $\mathrm{AI}$ in facility management in the energy sector. Furthermore, several countries are developing legislation and regulations to support the initiation and full adoption of AI-based technology, but this is not the case in Nigeria.

\section{Conclusion and Recommendations}

The study's primary objective is to assess AI awareness in facility management and to identify the prospects and challenges of adopting $\mathrm{AI}$ in the energy sector. Based on the data, the research finds a high level of awareness regarding the notion of $\mathrm{AI}$ in the energy sector. Also, awareness about some selected AI technologies, machine \& deep learning, robotics, and speech recognition had a high awareness level. Additionally, the study concludes that AI technologies with a high awareness level regarding applicability to facilities management in the energy sector are in advanced metering infrastructure, smart grid, network management, and fault prediction/detection. The study also concludes that improved energy management, efficiency and transparency, remote reading of energy meters, and improved planning, operation \& control of power systems were the most prevalent prospects of AI adoption. The critical challenges to AI deployment in the Nigerian energy sector are outdated power system infrastructure, 
cellular technologies, a scarcity of qualified experts and data scientists, growing threats from cyber-attacks, and AI dependence on electricity and internet connections.

Hence, the study recommends the following:

1. Improved awareness and technical know-how of energy sector personnel Increased awareness through conferences, workshops, and seminars for stakeholders in the power sector will boost the knowledge and awareness of AIbased technologies. These trainings would also enhance swift adoption when necessary infrastructures are provided.

2. Provision of adequate power system infrastructure to provide stable power supply

Most digital technologies, especially AI technologies, require an uninterrupted electricity supply for effective operation. Hence, unless the country is able to sufficiently address the issue of epileptic power supply, adoption of AI technologies will be impossible

3. Provision of reliable connectivity in a rural underserved area for constant data communication

Just like power supply, strong internet connectivity is another essential component of operating AI. Some urban cities and most rural settlements are still characterized by weak or very poor internet services, respectively. Hence, telecommunication providers need to improve and stabilize internet connectivity for enhanced AI adoption.

4. Funding fundamental and applied research to produce significant breakthroughs in AI theory, technology, and applications in the energy sector.

Adequate funding to support the massive infrastructural deficit to enable AItechnologies' active implementation and adoption cannot be overemphasized. In addition, research in the area of emerging AI technologies also requires funding to achieve breakthroughs in their applications.

5. Setup secure platforms and databases to promote data quality and private data exchange

Data security through secure databases to encourage investors and other stakeholders to venture into AI technologies in the energy industry cannot be overemphasized as well. This would curb the menace of cybercrime and boost confidence in AI operations. 


\section{$5 \quad$ Acknowledgment}

The authors wish to appreciate the energy sector practitioners across the North-central zone of Nigeria who participated in the survey. Their valid responses made the completion of the article possible.

\section{References}

[1] R. N. Robinson, Artificial Intelligence : Its Importance, Challenges and Applications in Nigeria. Direct Resources Journal Engineering Information Technology. 5(5), (2018) 36-41.

[2] A. Babuta, M. Oswald, \& A. Janjeva, Artificial Intelligence and UK National Security. Royal United Services Institute Occasional Paper, April 2020. (2020). ISSN 2397-0286.

[3] A. J. Falode, B. O. Faseke, \& C. Ikeanyichukwu, Artificial Intelligence: The Missing Critical Component in Nigeria's Security Architecture. (2021) Available at SSRN 3896657.

[4] S. K. Jha, J. Bilalovic, A. Jha, N. Patel, \& H. Zhang, Renewable energy: Present research and future scope of Artificial Intelligence. Renewable and Sustainable Energy Reviews, 77, (2017) 297-317.

[5] H. Yousuf, A. Y. Zainal, M. Alshurideh, \& S. A. Salloum, Artificial intelligence models in power system analysis. Studies in Computational Intelligence, 912, (2021) 231-242. https://doi.org/10.1007/978-3-030-51920-9_12

[6] A. Sozontov, M. Ivanova, \& A. Gibadullin, Implementation of artificial intelligence in the electric power industry. E3S Web of Conferences, 114(01009), 1-6. (2019) https://doi.org/10.1051/e3sconf/201911401009

[7] ConsultancyUK. Artificial Intelligence set to revolutionise energy \& utilities industry. Available online (https://www.consultancy.uk/news/16767/artificial-intelligence-set-to-revolutionise-energy-utilities-industry). (2018). Accessed on 8/11/2021

[8] S. Küfeoğlu, and M. Özkuran, Energy Consumption of Bitcoin Mining. Cambridge Working Papers in Economics, (2019) 1948.

[9] A. H. Sodhro, S. Pirbhulal, V. H. C. De Albuquerque, Artificial intelligence-driven mechanism for edge computing-based industrial applications. IEEE Trans. Ind. Informatics 15, (2019) 4235-4243. doi:10.1109/TII.2019.2902878.

[10] K. W. Kow, Y. W. Wong, R. K. Rajkumar, \& R. K. Rajkumar, A review on performance of artificial intelligence and conventional method in mitigating PV grid-tied related power quality events. Renewable and Sustainable Energy Reviews, 56, (2016) 334-346.

[11] A. Youssef, M. El-Telbany, \& A. Zekry, The role of artificial intelligence in photo-voltaic systems design and control: A review. Renewable and Sustainable Energy Reviews, 78, (2017) 72-79.

[12] M. Seyedmahmoudian, R. Rahmani, S. Mekhilef, A. M. T. Oo, A. Stojcevski, T. K. Soon, $\&$ A. S. Ghandhari, Simulation and hardware implementation of new maximum power point tracking technique for partially shaded PV system using hybrid DEPSO method. IEEE transactions on sustainable energy, 6(3), (2015) 850-862. 
[13] B. Yang, T. Yu, X. Zhang, H. Li, H. Shu, Y. Sang, \& L. Jiang, Dynamic leader based collective intelligence for maximum power point tracking of PV systems affected by partial shading condition. Energy Conversion and Management, 179, (2019) 286-303.

[14] T. Ahmad, D. Zhang, C. Huang, H. Zhang, N. Dai, Y. Song, \& H. Chen, (2021). Artificial intelligence in sustainable energy industry: Status Quo, challenges and opportunities. Journal of Cleaner Production, Volume 289, 125834, ISSN 0959-6526.

[15] B. Makala, \& T. Bakovic, Artificial Intelligence in the Power Sector. Available online: https://www.researchgate.net/publication/343624277. (2020) Assessed on 13/11/2021.

[16] Q. Li, Z. Y. Wu, \& A. Rahman, Evolutionary deep learning with extended Kalman filter for effective prediction modeling and efficient data assimilation. Journal of Computing in Civil Engineering, 33(3), (2019) 04019014.

[17] H. Demolli, A. S. Dokuz, A. Ecemis, \& M. Gokcek, Wind power forecasting based on daily wind speed data using machine learning algorithms. Energy Conversion and Management, 198, (2019) 111823.

[18] J. Hou, K. Ni, \& A. Hawari, An Artificial Neural Network Based Anomaly Detection Algorithm for Nuclear Power Plants. Transactions, 120(1), (2019) 219-222.

[19] P. Neupane, H. Kim, A Conceptual Framework of Facility Management with Intelligence for Sustainable Smart City. Master Thesi: University of Seoul (2020).

[20] I. A. Ajah, \& C. C. Chigozie-Okwum, Prospects of ICT for digital growth and national development in Nigeria. African Research Review, 13(3), (2019) 192-203.

[21] A. A. Tived, Artificial Intelligence in the Solar PV value chain : current applications and future prospects future prospects. Masters of Science thesis: KTH Industrial Engineering and Management (2020).

[22] H. Soonmin, A. Lomi, E. C. Okoroigwe, \& L. R. Urrego, Investigation of solar energy: The case study in Malaysia, Indonesia, Colombia and Nigeria. International Journal of Renewable Energy Research, 9(1), (2019) 86-95.

[23] T. Dhanabalan, T. A. Sathish, Transforming Indian industries through artificial intelligence and robotics in industry 4.0. International Journal of Mechanical Engineering and Technology, 9(10), (2018) 835-845

[24] C. R. Kothari Research Methodology - methods and techniques. Second Revised Edition. New Age International (P) Limited, Publishers 4835/24, Ansari Road, Daryaganj, New Delhi -110002 (2004).

[25] G. Devault, Advantages and Disadvantages of Quantitative Research. Available online: http://www.thebalancesmb.com. (2020) Assessed on 13/11/2021.

[26] A. A. Olanrewaju, J. P Anahve, Duties and responsibilities of quantity surveyors in the Procurement of Building Services Engineering: December, 2015, Procedia Engineering 123: (2015) 352-360, DOI: 10.1016/j.proeng.2015.10.046).

[27] C. C. Adindu, U. O. Ajator, N. N. Agu, V. N. Okorie, \& S. O. Yusuf, Enriching Quantity Surveying Curriculum for Leadership in the Built Environment. Proceedings of the 5th Research Conference of the NIQS (RECON 5), (2020) 315-331

[28] K. Wakunuma, T. Jiya, \& S. Aliyu, Socio-ethical implications of using AI in accelerating SDG3 in Least Developed Countries. Journal of Responsible Technology, 4, (2020) 100006. 
[29] N. Kshetri, Artificial intelligence in developing countries. IEEE Annals of the History of Computing, 22(04), (2020) 63-68.

\section{$7 \quad$ Authors}

Jonathan O. Mobayo is a junior-level product manager and a researcher with interests in construction, digitalization, procurement, and more to be explored. Jonathan had his first degree in Project Management from the Federal University of Technology, Akure. He is currently affiliated with the Federal University of Technology, Minna as a Masters's student of Project Management.

Ayooluwa Femi Aribisala is a data analyst and researcher. He holds a B.Eng (Electrical/Electronic Engineering) from Ekiti State University and a Masters degree in Project Management from the Federal University of Technology Minna. His research interest is centered on Engineering Management in the energy sector. Email: aribisala2016@gmail.com

Saheed Olanrewaju Yusuf is a Lecturer in the Department of Project Management Technology, FUT Minna He holds a B.Eng (Civil Engineering) from the University of Ilorin, and MTech (Project Management) from the Federal University of Technology Minna. He has several publications in peer-reviewed international journals and refereed international conferences. Email: so.yusuf@futminna.edu.ng

Usman Belgore holds a B.Tech (Quantity Surveying), M.Tech (Project Management) from FUT Minna, and an MBA. He is a chartered member of the NIQS, Registered Quantity Surveyor, Member of the Royal Institution of Chartered Surveyors, Associate Member of the Chartered Institute of Arbitrators (UK). He has experience spanning telecommunication, banking, and construction. Email: usmanbelgore@yahoo.com 